\title{
Kinetic of Adsorption Process of Sulfonated Carbon- derived from Eichhornia crassipes in the Adsorption of Methylene Blue Dye from Aqueous Solution
}

\author{
Mukhamad Nurhadi'1,*, Iis Intan Widiyowati1 ${ }^{1}$ W. Wirhanuddin ${ }^{1}$, Sheela Chandren ${ }^{2,3}$ \\ ${ }^{1}$ Department of Chemical Education, Universitas Mulawarman, Kampus Gunung Kelua, Samarinda, \\ 75123, East Kalimantan, Indonesia \\ ${ }^{2}$ Department of Chemistry, Faculty of Science, Universiti Teknologi Malaysia, 81310 Johor Bahru, \\ Johor, Malaysia \\ ${ }^{3}$ Centre for Sustainable Nanomaterials, Ibnu Sina Institute for Scientific and Industrial Research, \\ Universiti Teknologi Malaysia, 81310 Johor Bahru, Johor, Malaysia
}

Received: 20th April 2018; Revised: 28th August 2018; Accepted: 4th September 2018; Available online: 25th January 2019; Published regularly: April 2019

\begin{abstract}
The evaluation of kinetic adsorption process of sulfonated carbon-derived from Eichhornia crassipes in the adsorption of methylene blue dye from aqueous solution has been carried out. The sulfonated carbon-derived from E. crassipes (EGS-600) was prepared by carbonation of $E$. crassipes powder at $600{ }^{\circ} \mathrm{C}$ for $1 \mathrm{~h}$, followed by sulfonation with concentrated sulfuric acid for $3 \mathrm{~h}$. The physical properties of the adsorbents were characterized by using Fourier transform infrared spectroscopy, X-ray diffraction (XRD), scanning electron microscopy (SEM), and nitrogen adsorption-desorption studies. Adsorption study using methylene blue dye was carried out by varying the contact time and initial dye concentration for investigated kinetics adsorption models. The effect of varying temperature was used to determine the thermodynamic parameter value of $\Delta \mathrm{G}, \Delta \mathrm{H}$, and $\Delta \mathrm{S}$. The results showed that the equilibrium adsorption capacity was $98 \%$ when EGS-600 is used as an adsorbent. The methylene blue dye adsorption onto adsorbent takes place spontaneity and follows a pseudo-second-order adsorption kinetic model. Copyright (C) 2019 BCREC Group. All rights reserved
\end{abstract}

Keywords: Eichhornia crassipes (water hyacinth); methylene blue; adsorption; sulfonation; carbon

How to Cite: Nurhadi, M., Widiyowati, I.I., Wirhanuddina, W., Chandren, S. (2019). Kinetic of Adsorption Process of Sulfonated Carbon-derived from Eichhornia crassipes in the Adsorption of Methylene Blue Dye from Aqueous Solution. Bulletin of Chemical Reaction Engineering \& Catalysis, 14 (1): 17-27 (doi:10.9767/bcrec.14.1.2548.17-27)

Permalink/DOI: https://doi.org/10.9767/bcrec.14.1.2548.17-27

\section{Introduction}

Every year, more than 100,000 kinds of synthetic dyestuff from textile, paper, rubber, plastic, leather, cosmetic, pharmaceutical and food industries are discharged as liquid waste in

* Corresponding Author.

E-mail address: mukh.nurhadi1969@gmail.com (M. Nurhadi)

Telp. : +62 541 743651; Fax: +62 541743929 large volumes. Methylene blue dye is a type of synthetic dye, which is widely used in coloring papers, as temporary hair colorant, and for dyeing cotton and wool [1]. The disposal of liquid dye waste from industry to environment (river and lake) can cause serious ramifications on the environment and the health of living beings. The colored wastewater in the environment can cause infertility of the soil, increased amount of chemical oxygen demand (COD) in water, and 
reduced light penetrability that can influence the photosynthetic processes of aquatic plants $[2,3]$. Apart from that, studies have also shown that many synthetic dyestuff are harmful and even carcinogenic, which can pose serious hazards to the health of living beings, such as heartbeat increase, vomiting, shock, cyanosis, jaundice, quadriplegia, and tissue necrosis in human $[2,4]$.

Many researchers have investigated the usage of different methods in removing synthetic dyestuff from wastewater to reduce their impact on the environment. Among the methods that have been used to discharge synthetic dyestuff in wastewater treatment are physicochemical, chemical, and biological methods, such as: coagulation and flocculation [5-7], adsorption [8-10], ozonation [11], electrochemical [5], fungal decolorization [12], microbiological or enzymatic decomposition [13].

Adsorption is a physicochemical method of treating aqueous effluent that is rapidly gaining prominence due to its proven efficiency and great potential as means of producing quality effluent [14]. Activated carbon is an example of an adsorbent, which is effective and widely used to dispose of synthetic dyestuff in wastewater treatment $[15,16]$. However, the cost of its commercial application is still very high [15]. This has prompted many researchers to try out cheaper and more efficient alternative materials, such as: agricultural residues [4], clay minerals [1,7], cashew nut shell [3], fly ash [17], peat [10], yellow passion fruit peel [9], fish bones [18], wood powder and lignin [16,19].

E. crassipes (water hyacinth) is a weed plant with a high growth rate that can damage the aquatic environment, such as: in many tropical lake and river [20]. Its existence can disrupt fisheries, transportation and hydroelectric power production [14]. Many researchers have attempted to looking for low cost adsorbent from $E$. crassipes for adsorption dye, such as: adsorption of congo red dye from aqueous solutions using roots of E. crassipes [14], biosorption of basic dyes by E. crassipes root [21], removal of azo and anthraquinone dye from aqueous solutions by E. crassipes [20], and activated carbon prepared from E. crassipes as an ad- sorbent for the removal of dye from aqueous solution [15]. Nevertheless, adsorbents used by previous researches consist of powder with varying particle sizes and activated carbon that was thermally activated.

In the present study, we have prepared adsorbent from $E$. crassipes which is activated not only by thermal activation but also chemical activation by using concentrated sulfuric acid. Thermal activation or carbonation process was carried out to transform the $E$. crassipes powder to carbon. The activation by concentrated sulfuric acid or sulfonation process was to enhance the number of oxygen functional groups that can serve as the adsorption sites, while increasing hydrophilicity [22]. In this research, the effect of contact time and initial concentration of methylene blue were used to determine equilibrium adsorption capacity and to investigate the kinetic process in the adsorption by Lagergren and Svenska equation. The effect of temperature was used to study the parameter of thermodynamic of methylene blue dye adsorption process by Van't Hoffs plots. In this research the effects of $\mathrm{pH}$ of solution and dosage of adsorbent were also investigated.

\section{Materials and Method}

\subsection{Carbonation Process}

The fresh E. crassipes trunks were collected from a pool around Mulawarman University and washed with tap water to remove impurities. Then, it was cut and dried in the oven at $110{ }^{\circ} \mathrm{C}$ overnight. The dry trunks were blended to form powder which was labeled as EG. Subsequently, the powder was carbonated by heating in a furnace at $600^{\circ} \mathrm{C}$ for $1 \mathrm{~h}$.

\subsection{Sulfonation Process}

The carbon obtained from E. crassipes was sulfonated by using $6 \mathrm{~mL}$ of concentrated sulfuric acid (98\%, JT Baker) per gram sample. The mixture was stirred at room temperature for $3 \mathrm{~h}$. Any loosely-bound acid were removed from the sample by washing with distilled water. The sample was then dried overnight in an oven at $110{ }^{\circ} \mathrm{C}$ [23-25]. The sulfonated carbon from E. crassipes was labeled as EGS-600. The

Table 1. Codes and treatments done to the samples

\begin{tabular}{lcccc}
\hline Samples & $\begin{array}{c}\text { Type of } \\
\text { treatment }\end{array}$ & $\begin{array}{c}\text { Time of sulfonation } \\
(\mathrm{h})\end{array}$ & $\begin{array}{c}\text { Temperature of } \\
\text { carbonation } \\
\left({ }^{\circ} \mathrm{C}\right)\end{array}$ & Time of carbonation (h) \\
\hline EG & - & - & - & - \\
EGS-600 & Sulfonation & 3 & 600 & 1 \\
\hline
\end{tabular}


codes of the adsorbents are given in Table 1.

\subsection{Samples Characterization}

The properties of sulfonated carbon from $E$. crassipes were determined by using Fourier transform infrared spectroscopy, X-ray diffraction (XRD), scanning electron microscopy (SEM), and nitrogen adsorption-desorption studies. The functional groups in the sulfonated carbon were determined by FTIR spectroscopy using a Prestige 21 Shimadzu. Crystallinity and phase content of the samples were determined by X-ray diffractometer (XRD) using a Phillips PANalytical X'Pert PRO type, with the $\mathrm{Cu}-\mathrm{Ka}(\lambda=1.5406 \AA)$ radiation. The surface morphology was investigated by SEM images obtained using a JEOL JSM-6510. Data from a Quantachrome nova 1200 e instrument were used as the base to determine nitrogen adsorption-desorption isotherms, surface area, micropore area and pore size distribution.

\subsection{Adsorption Test}

The adsorption ability of the samples was carried out by mixing the samples $(0.125 \mathrm{~g})$ with $25 \mathrm{~mL}$ of methylene blue dye solution $\left(\mathrm{C}_{16} \mathrm{H}_{18} \mathrm{ClN}_{3} \mathrm{~S} ; 100 \mathrm{mg} . \mathrm{L}^{-1}\right)$ in a $100 \mathrm{~mL}$ beaker glass at room temperature for the durations of $5,10,15,20,25,30,60,120,240,480$, and 720 min. After the adsorption test, the solid adsorbent was separated from the filtrate by centrifugation technique. The residual dye was analyzed by using a UV-Vis spectrophotometer by monitoring the changes in absorbance of solu-

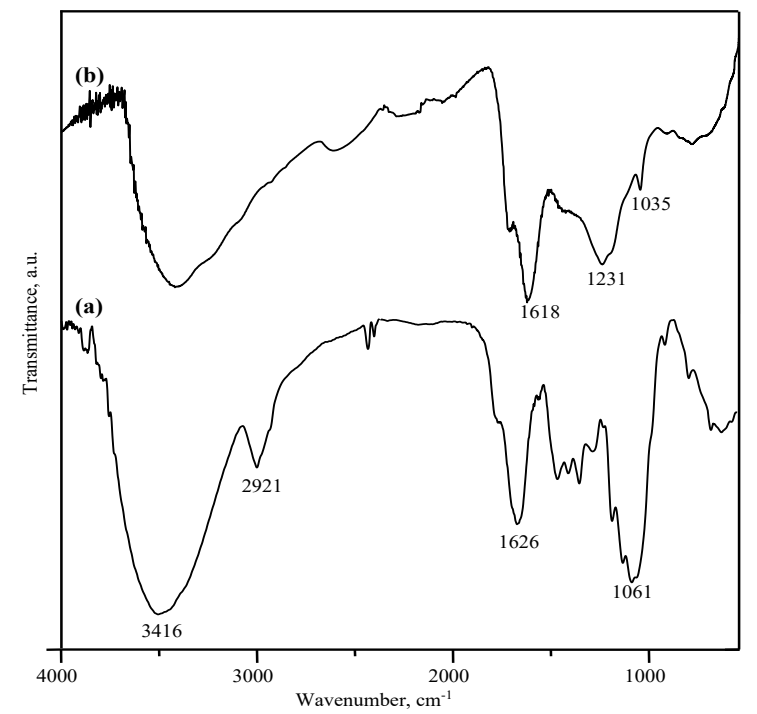

Figure 1. FTIR spectra of (a) EG and (b) EGS-600 tion at $660 \mathrm{~nm}$. The effect of sorbate to sorbent ratio for the percentage and unit dye sorbate sorption capacity of the sulfonated carbon from $E$. crassipes was investigated by varying the dose of sorbent between 0.0625-0.125 g. The effect of $\mathrm{pH}$ on the dye sorption by sulfonated carbon from $E$. crassipes was evaluated in the $\mathrm{pH}$ range of 1.0-12.0. The initial $\mathrm{pH}$ of dye solution was fixed by the mixing $0.1 \mathrm{M} \mathrm{HCl}$ and $0.1 \mathrm{M} \mathrm{NaOH}$. Apart from that, different initial dye concentrations (80, 100, and 120 mg.L $\mathrm{L}^{-1}$ ) were also investigated in this the study. Powder and carbon from $E$. crassipes were also tested as comparison.

The adsorption efficiency of the adsorbent was calculated using this equation:

$$
\text { Adsorption efficiency }(\%)=\frac{\left(C_{0}-C_{t}\right)}{C_{0}} \times 100 \%
$$

where, $C_{0}$ and $C_{t}$ are the initial and the dye concentration after adsorption time $t$ (mg. $\left.\mathrm{L}^{-1}\right)$ in the solution, respectively. The adsorption capacity $q_{t}$ of $E$. crassipes adsorbent as milligram per gram of adsorbent $(\mathrm{mg} / \mathrm{g})$ was determined with this equation:

$$
q_{t}=\left(C_{0}-C_{t}\right) \frac{V}{W}
$$

where $V$ is the volume of dye solution $(\mathrm{mL})$ and $W$ is weight adsorbent (g).

\section{Results and Discussion}

\subsection{Physical Properties}

The FTIR spectra for EG and EGS-600 are shown in Figure 1. The broad band at 3416

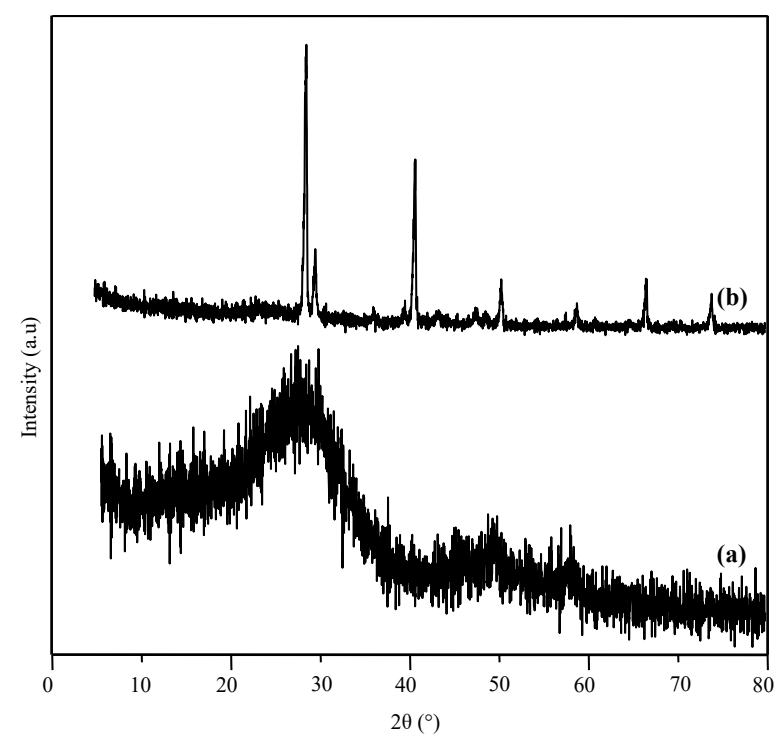

Figure 2. XRD pattern of (a) EG and (b) EGS-600 
$\mathrm{cm}^{-1}$ that was detected in all of the FTIR spectra, is assigned to the $\mathrm{O}-\mathrm{H}$ stretching mode of the $-\mathrm{COOH}$ and phenolic - $\mathrm{OH}$ groups [23]. The amount of $-\mathrm{OH}$ groups in the samples decreases when the powder of Eichhornia crassipes (water hyacinth) was carbonated and sulfonated. The adsorption peaks at $2919 \mathrm{~cm}^{-1}$ is attributed to $\mathrm{C}-\mathrm{H}$ (aliphatic) stretching vibration. This adsorption peak of $\mathrm{C}-\mathrm{H}$ disappeared when the adsorbent was carbonated and sulfonated. The effect of sulfonation process on the adsorbent can also be proven by the attachment of $-\mathrm{SO}_{3} \mathrm{H}$ groups. This was indicated by the adsorption band at $1034 \mathrm{~cm}^{-1}, \mathrm{~S}=\mathrm{O}$ stretching and $1231 \mathrm{~cm}^{-1}$, stretching in $-\mathrm{SO}_{3} \mathrm{H}$ [26]. The increasing of amount of $\mathrm{S}=\mathrm{O},-\mathrm{SO}_{3} \mathrm{H}$ functional groups and releasing of $\mathrm{C}-\mathrm{H}$ onto EGS600 surface can increase its polarity properties. The adsorption peak of aromatic $\mathrm{C}=\mathrm{C}$ stretching mode in polyaromatics is indicated by the vibration band at $1626 \mathrm{~cm}^{-1}$.

The XRD pattern in Figure 2a shows that $E$. crassipes powder (EG) has low crystallinity. Amorphous carbon, which is composed of aromatic carbon sheets, can be observed in E. crassipes powder by the broad peak at $2 \theta$ value of $10-30^{\circ}(\mathrm{C}(200))$ [27]. After carbonation and sulfonation, the crystallinity of E. crassipes increased significantly, as can be seen by the XRD pattern at Figure $2 b$. Both XRD patterns showed a sharp crystalline peaks at $2 \theta$ value of $28.6^{\circ}, 40.8^{\circ}, 50.3^{\circ}, 66.7^{\circ}$, and $74.1^{\circ}$, which can be assigned to calcite [28].

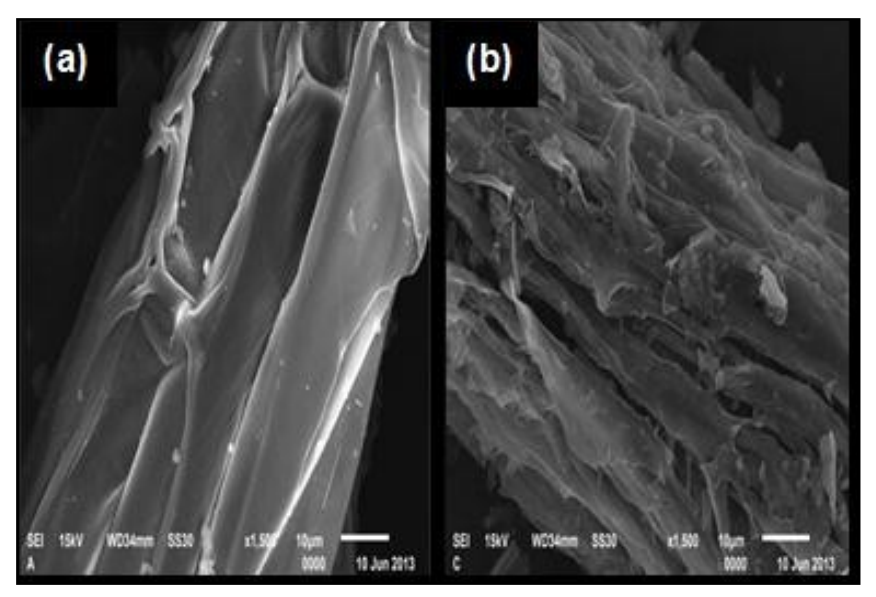

Figure 3. SEM Image of (a) EG and (b) EGS-600
The SEM images of EG and EGS-600 are shown in Figure 3. The SEM images show that the EG and EGS-600 are in the fiber form, which are arranged as fibrils. Hollow spaces started to appear after the E. crassipes was carbonated and sulfonated. The surface morphology of E. crassipes powder (EG) is smooth, but turned rough after being carbonated and sulfonated (EGS-600).

The $\mathrm{N}_{2}$ adsorption-desorption isotherms for EG and EGS-600 are shown in the Figure 4. All the isotherms are of type III and can be attributed to the relatively weak adsorbentadsorbate interaction. The adsorbed molecules are clustered around the most favorable sites. The other physical properties of EG and EGS600 obtained from this analysis, such as BET surface area, pore volume, mean pore size, and
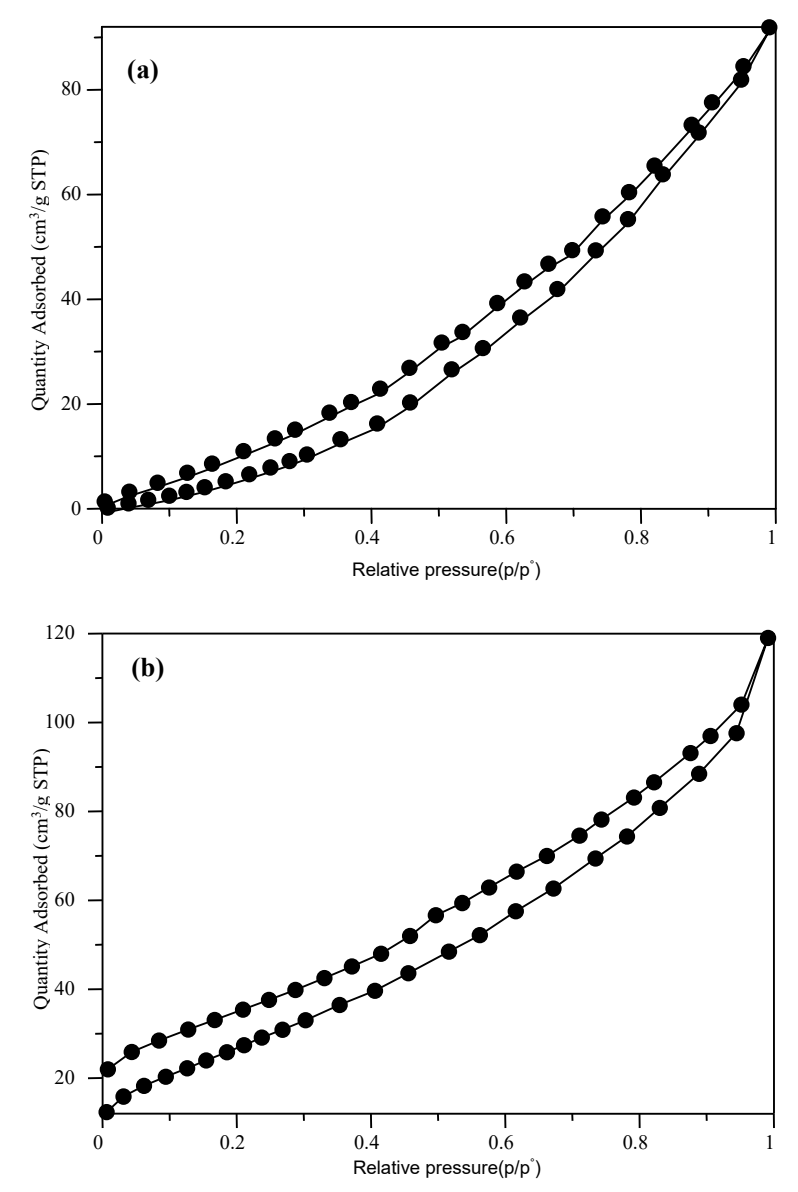

Figure 4. $\mathrm{N}_{2}$ adsorption-desorption isotherms of (a) EG and (b) EGS-600

Table 2. Physical properties of EG and EGS-600

\begin{tabular}{lcccc}
\hline Samples & $\begin{array}{c}\text { BET surface area } \\
\left(\mathrm{m}^{2} \cdot \mathrm{g}^{-1}\right)\end{array}$ & $\begin{array}{c}\text { Pore Volume } \\
\left(\mathrm{cm}^{3} \cdot \mathrm{g}^{-1}\right)\end{array}$ & $\begin{array}{c}\text { Mean pore size } \\
(\mathrm{nm})\end{array}$ & $\begin{array}{c}\text { Micropore Area } \\
\left(\mathrm{m}^{2} \cdot \mathrm{g}^{-1}\right)\end{array}$ \\
\hline EG & 123.79 & 14.22 & 22.97 & 57.54 \\
EGS-600 & 70.31 & 13.34 & 37,95 & 14.56 \\
\hline
\end{tabular}


micropore area, are given in Table 2. The BET surface area, pore volume, mean pore size and micropore area of EG and EGS-600 showed the following values; $123.79 \mathrm{~m}^{2} \cdot \mathrm{g}^{-1}, 14.22 \mathrm{~cm}^{3} \cdot \mathrm{g}^{-1}$, $22.97 \mathrm{~nm}, 57.544 \mathrm{~m}^{2} . \mathrm{g}^{-1}$ and $70.31 \mathrm{~m}^{2} . \mathrm{g}^{-1}, 13.34$ $\mathrm{cm}^{3} \cdot \mathrm{g}^{-1}, 37.95 \mathrm{~nm}, 14.56 \mathrm{~m}^{2} \cdot \mathrm{g}^{-1}$, respectively. It can be seen that the BET surface area and micropore area decreased slightly when E. crassipes powder was carbonated and sulfonated.

\subsection{Effect of Contact Time}

Figure 5 shows the effect of contact time on the adsorption of methylene blue on EG and EGS-600 adsorbents. These results indicate that the equilibrium adsorption was reached within 20 min by both adsorbents and dye removal percentage increased with increasing contact time. Both adsorbents rapidly adsorbed methylene blue within the first 5 min of contact time with adsorption capacity of $86 \%$ for EG and $92 \%$ for EGS-600. After 5 min, the changes in adsorption capacity increased gradually until the equilibrium was achieved within $20 \mathrm{~min}$, with adsorption percentage of $90 \%$ for EG and $98 \%$ for EGS-600. The percentage of dye removal for EG was lower than EGS-600. This phenomenon was probably caused by the physical properties of EG on the surface, which was dominated by micropores. The small sizes of the pores may have hindered the effective adsorption of the methylene blue dye on the adsorbent surface. And also the increase of the amount of $-\mathrm{OH},-\mathrm{COOH}, \mathrm{S}=\mathrm{O},-\mathrm{SO}_{3} \mathrm{H}$ functional groups onto EGS-600 surface which can become active site when adsorption of methylene blue dye in aqueous solution was done.

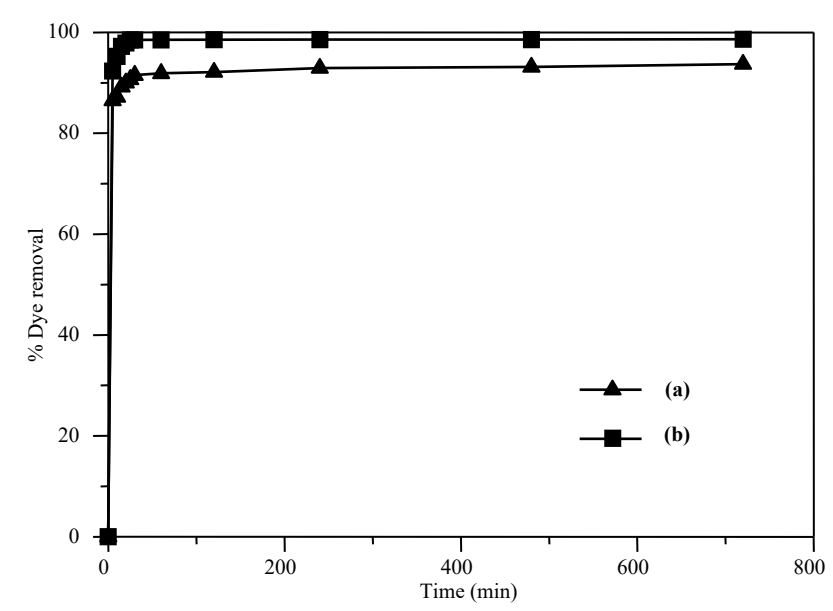

Figure 5. Effect of contact time on \% Methylene Blue dye removal on (a) EG and (b) EGS-600 Conditions: (pH: 6.9, MB: $100 \mathrm{mg} \cdot \mathrm{L}^{-1}$, weight of adsorbent: $125 \mathrm{mg}$, at $25^{\circ} \mathrm{C}$ )
Comparison of the adsorption process onto EG and EGS-600 can be illustrated in Figure 6.

\subsection{Adsorption Kinetics}

In removing dyes from coloured wastewater, it is important to evaluate the adsorption mechanism and potential rate control measures that control the adsorption rate. To investigate the controlling rate of adsorption mechanism process, mass transfer and two kinetic models were tested out.

The adsorption kinetic of dye adsorption by powder and sulfonated carbon-derived from $E$. crassipes was investigated by pseudo-firstorder and pseudo-second-order kinetic equation which were introduced by Lagergren and Svenska $[2,14]$. The pseudo-first-order equation can be expressed as follows:

$$
\frac{d q}{d t}=k_{1, \text { ad }}\left(q_{e}-q\right)
$$

after integration with boundary condition $t=0$ to $t=t$ and $q=0$ to $q=q_{t}$, it obtained the integrated form as:

$$
\log \left(q_{e}-q_{t}\right)=\log q_{e, \mathrm{cal}}-\frac{k_{1, \mathrm{ad}}}{2.303} t
$$

where $k_{1}\left(\mathrm{~g} \cdot \mathrm{mg}^{-1} \cdot \mathrm{h}^{-1}\right)$ is the rate constant for the pseudo-first-order adsorption, $q_{e}$ and $q_{t}$ are the amounts of dye adsorbed per gram of adsorbent $(\mathrm{mg} / \mathrm{g})$ at equilibrium and any time $t$. The plot of $t$ versus $\log \left(q_{e^{-}} q_{t}\right)$ was used to calculate $q_{e, c a l}$ from slope and $k_{1}$ from intercept.

The pseudo-second-order can be expressed as equation:

$$
\frac{d q}{d t}=k_{2, \text { ad }}\left(q_{e}-q\right)
$$
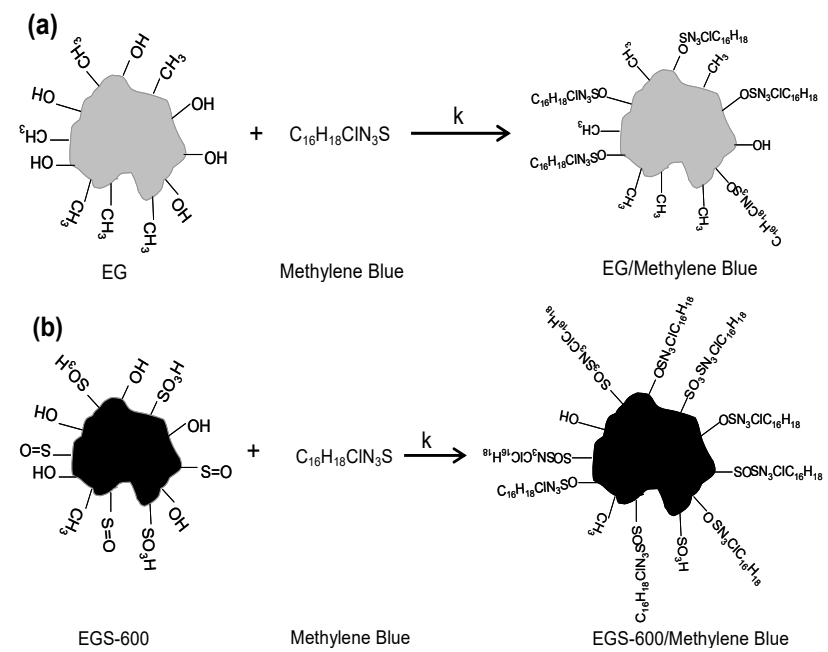

Figure 6. The illustration of methylene blue adsorption process onto (a) EG and (b) EGS-600 adsorbent 


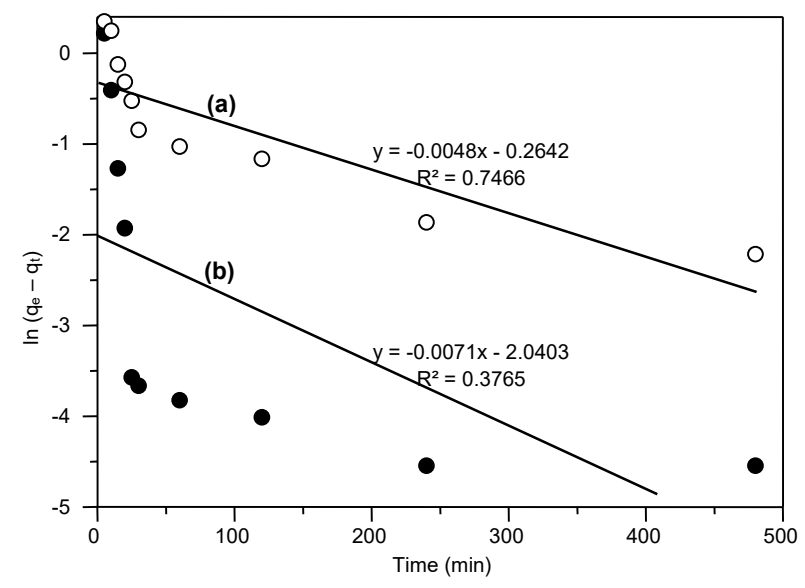

Figure 7. Pseudo-first-order kinetics plot for the adsorption of methylene blue dye onto (a) EG and (b) EGS-600 adsorbent. Conditions: (pH: 6.9, MB: $100 \mathrm{mg} \cdot \mathrm{L}^{-1}$, weight adsorbent: $125 \mathrm{mg}$, at $25^{\circ} \mathrm{C}$ )

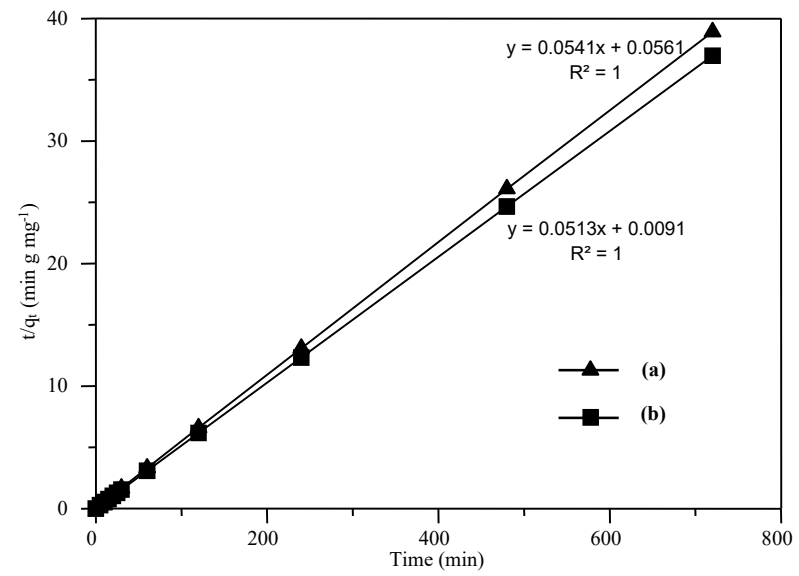

Figure 8. Pseudo-second-order kinetics plot for the adsorption of methylene blue dye onto (a) EG and (b) EGS-600 adsorbent. Conditions: (pH: 6.9, MB: $100 \mathrm{mg} . \mathrm{L}^{-1}$, weight adsorbent: $125 \mathrm{mg}$, at $25^{\circ} \mathrm{C}$ )

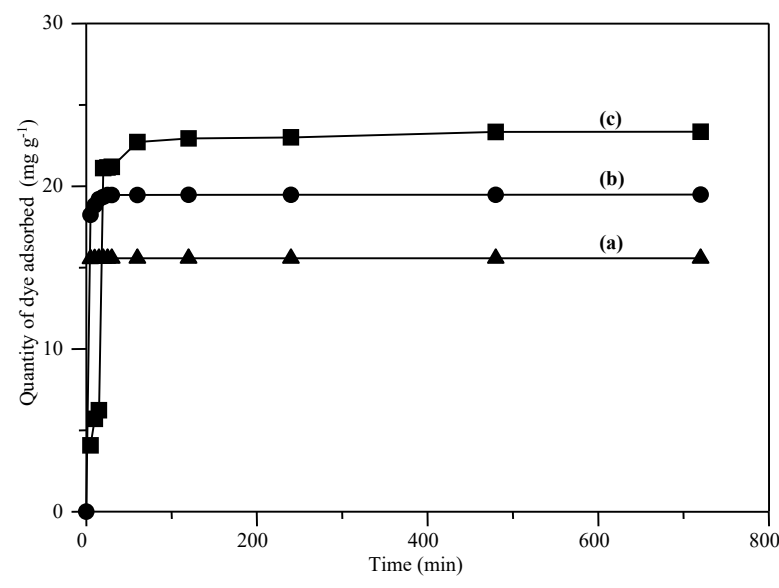

Figure 9. Effect of initial dye concentration on sorption of Methylene blue. Conditions: ( $\mathrm{pH}: 6.9$, MB: (a) $80 \mathrm{mg} \cdot \mathrm{L}^{-1}$, (b) $100 \mathrm{mg} \cdot \mathrm{L}^{-1}$ (c) $120 \mathrm{mg} \cdot \mathrm{L}^{-1}$, weight adsorbent: $125 \mathrm{mg}$, at $25^{\circ} \mathrm{C}$ )

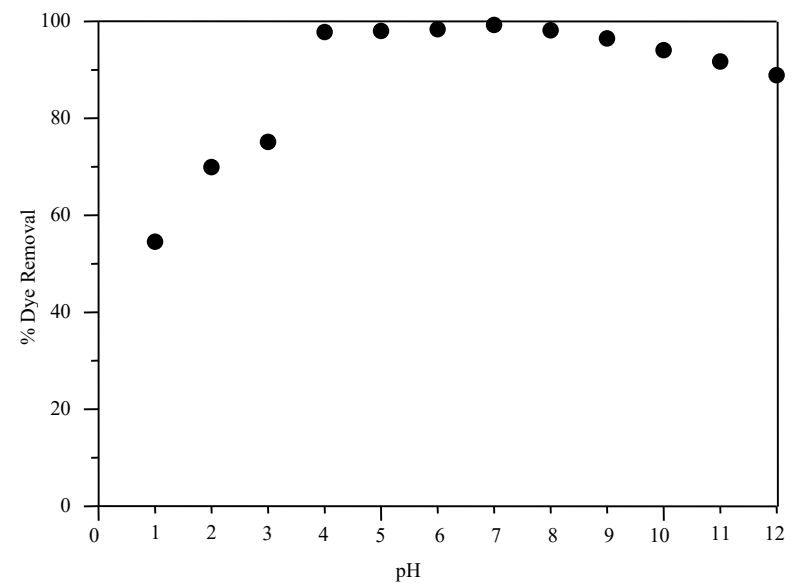

Figure 10. Effect of $\mathrm{pH}$ on \% Methylene Blue dye removal on EGS-600, Conditions: (MB: 100 mg. $\mathrm{L}^{-1}$, weight adsorbent: $125 \mathrm{mg}$, at $25^{\circ} \mathrm{C}$ )

Table 3. Kinetic parameter of the pseudo-first-order and pseudo-second-order models for adsorption of Methylene blue dye of EG and EGS-600

\begin{tabular}{|c|c|c|c|c|c|c|c|c|}
\hline \multirow[b]{2}{*}{$\begin{array}{l}\text { Eichhornia } \\
\text { crassipes } \\
\text { Adsorbent }\end{array}$} & \multicolumn{4}{|c|}{ Pseudo-first-order } & \multicolumn{4}{|c|}{ Pseudo-second-order } \\
\hline & $\begin{array}{c}q_{e} \\
\text { Calculation } \\
\left(\mathrm{mg} \cdot \mathrm{g}^{-1}\right)\end{array}$ & $\begin{array}{c}q_{e} \\
\text { experiment } \\
\left(\mathrm{mg} \cdot \mathrm{g}^{-1}\right)\end{array}$ & $\begin{array}{c}k_{1} \\
\left(\text { g.mg }{ }^{-1} \cdot \mathrm{min}^{-1}\right)\end{array}$ & $\mathrm{R}^{2}$ & $\begin{array}{c}q_{e} \\
\text { Calculation } \\
\left(\mathrm{mg} \cdot \mathrm{g}^{-1}\right)\end{array}$ & $\begin{array}{c}q_{e} \\
\text { experiment } \\
\left(\mathrm{mg} \cdot \mathrm{g}^{-1}\right)\end{array}$ & $\begin{array}{c}k_{2} \\
\left(\text { g.mg }{ }^{-1} \cdot \min ^{-1}\right)\end{array}$ & $\mathrm{R}^{2}$ \\
\hline EG & 0.769 & 18.982 & 0.0048 & 0.746 & 18.484 & 18.517 & 0.0521 & 1.000 \\
\hline EGS-600 & 0.129 & 19.480 & 0.0071 & 0.376 & 19.493 & 19.480 & 0.2891 & 1.000 \\
\hline
\end{tabular}


after integration with boundary condition $t=0$ to $t=t$ and $q=0$ to $q=q_{t}$, the new equation form can be written as:

$$
\frac{t}{q_{t}}=\frac{1}{k_{2} q_{e, \mathrm{cal}}^{2}}+\frac{t}{q_{e, \mathrm{cal}}}
$$

where, $k_{2}\left(\mathrm{~g} \cdot \mathrm{mg}^{-1} \cdot \mathrm{h}^{-1}\right)$ is the rate constant for the pseudo-second-order adsorption. The plot $t$ versus $t / q_{t}$ was used to calculate $q_{e, c a l}$ from slope and $k_{2}$ from intercept.

The Freundlich isotherm equation was used to determine the adsorption isotherm of powder and sulfonated carbon-derived from E. crassipes. The Freundlich equation is followed as:

$$
\begin{aligned}
q_{e} & =K_{F} C_{e}^{1 / n} \\
\ln q_{e} & =\ln K_{F}+(1 / n) \ln C_{e}
\end{aligned}
$$

Based on the intercept and slope of the plot of $\ln q_{e}$ vs $\ln C_{e}$, the $K_{F}$ and $n$ can be calculated. In this relation, $K_{F}\left(\mathrm{mg} \cdot \mathrm{g}^{-1}\right)\left(\mathrm{L}^{\mathrm{mg}} \mathrm{m}^{-1}\right)^{1 / n}$, which indicate a measure of adsorption capacity and $1 / n$ indicate the favorability of adsorption. If the value of $n>1$, it characterizes favorable adsorption condition.

The pseudo-first-order and pseudo-secondorder kinetics plots of both EG and EGS-600 as adsorbent of methylene blue dye are shown in Figures 7 and 8 , respectively. The rate constant $(k)$, equilibrium sorption calculated $\left(q_{e, c a l}\right)$ were determined by slope and intercept of the plots. The value of rate constant $(k)$, equilibrium sorption calculated $\left(q_{e, c a l}\right)$, equilibrium sorption experiment $\left(q_{e, e x p}\right)$ and the correlation coeffi-

Table 4. Freundlich isotherm constans for adsorption of Methylene blue dye on EG and EGS-600 adsorbent

\begin{tabular}{lccc}
\hline $\begin{array}{l}\text { Eichhornia crassipes } \\
\text { Adsorbent }\end{array}$ & $K_{F}$ & $n$ & $\mathrm{R}^{2}$ \\
\hline EG & 0.2101 & 1.011 & 0.9996 \\
EGS-600 & 0.2471 & 1.049 & 0.9935 \\
\hline
\end{tabular}

cients $\left(\mathrm{R}^{2}\right)$ were listed in Table 3 . The value of the correlation coefficient $\left(\mathrm{R}^{2}\right)$ for pseudo-firstorder of EG and EGS-600 as 0.746 and 0.376 were lower compared with the value for pseudo-second-order of both adsorbent as 1.000 which seen to be more accurate. This phenomenon is in line with result of Ho and McKay [29], that concluded the first order equation of Lagergren is not suitable well with the whole range of contact time and is generally applicable over the initial stage of the adsorption process in many cases. The result of this research showed that the adsorption of methylene blue onto EG and EGS-600 adsorbents were not following the pseudo-first-order kinetic.

On the other hand, the value of rate constant $(k)$, equilibrium sorption calculated $\left(q_{e, c a l}\right)$, equilibrium sorption experiment $\left(q_{e, e x p}\right)$ and the correlation coefficients $\left(\mathrm{R}^{2}\right)$ for pseudo-secondorder of EG and EGS-600 showed the following values; $0.0521 \mathrm{~g} \cdot \mathrm{mg}^{-1} \cdot \mathrm{min}^{-1}, \quad 1.000, \quad 18.484$ mg.g ${ }^{-1}, 18.517$ mg.g ${ }^{-1}$ for EG and 0.2891 g. $\mathrm{mg}^{-1} \cdot \mathrm{min}^{-1}, \quad 1.000, \quad 19.493 \quad \mathrm{mg} \cdot \mathrm{g}^{-1}, \quad 19.480$ mg.g ${ }^{-1}$ for EGS-600, respectively. It can be seen that the correlation coefficients for pseudosecond-order models for both EG and EGS-600 were very high $\left(\mathrm{R}^{2} \sim 1.000\right)$ and the difference in calculated equilibrium adsorption capacity, $q_{e, c a l}$ with experimental equilibrium adsorption capacity, $q_{e, e x p}$ for both adsorbents in pseudosecond-order were lower compared to pseudofirst-order. Therefore, it can be concluded that the adsorption of methylene blue dye onto both EG and EGS-600 adsorbents follow the pseudosecond-order adsorption mechanism model.

The heterogeneous adsorption process on the surface of both powder (EG) and sulfonated carbon (EGS-600) from E. crassipes, which was done through a multi-layer adsorption mechanism, can be described by using the Freundlich Isotherm model. The constant of Freundlich isotherm $\left(K_{F}\right)$ and $n$ value are presented in Table 4 . The values of $n$ are more than 1 , which indicates a favorable adsorption of methelyne blue dye on both of the adsorbents.

Table 5 Pseudo-second-order models parameter for adsorption of Methylene blue dye of EGS-600 on different initial concentration

\begin{tabular}{ccccc}
\hline $\begin{array}{c}\text { Initial Concentration of } \\
\text { Methylene Blue } \\
\left(\mathrm{mg.L}^{-1}\right)\end{array}$ & $\begin{array}{c}q_{e} \text { calculation } \\
\left(\mathrm{mg} \cdot \mathrm{g}^{-1}\right)\end{array}$ & $\begin{array}{c}q_{e} \text { experiment } \\
\left(\mathrm{mg} \cdot \mathrm{g}^{-1}\right)\end{array}$ & $\begin{array}{c}k_{2} \\
\left(\mathrm{~g} \cdot \mathrm{g}^{-1} \cdot \mathrm{min}^{-1}\right)\end{array}$ & $\mathrm{R}^{2}$ \\
\hline 120 & 23.981 & 23.348 & 0.0028 & 0.9967 \\
100 & 19.493 & 19.480 & 0.2892 & 1.0000 \\
80 & 15.576 & 15.566 & 13.738 & 1.0000 \\
\hline
\end{tabular}




\subsection{Effect of Initial Concentration}

Figure 9 shows the effect of different initial methylene blue dye concentrations on the adsorption. The adsorption amount of methylene blue increased when the initial concentration of methylene blue increased. At equilibrium, the amount methylene blue adsorbed increased from 15.57 to 23.35 when the initial concentration of methylene blue increased from 80 to 120 mg. $\mathrm{L}^{-1}$. It is hypothesized that the increasing concentration acted as an increasing driving force to overcome all mass transfer resistances of the methylene blue dye molecules between the aqueous and solid phase, leading to an increasing equilibrium sorption until saturation was achieved. A similar trend was also reported with methylene blue onto roots, stems and leaves with methylene blue concentrations of 0.80 to $8.0 \mathrm{mg} . \mathrm{L}^{-1}$ [2].

As another evident that adsorption process of methylene blue onto sulfonated carbonderived from $E$. crassipes take pseudo-secondorder kinetic models were done the effect of initial concentration. The data show that the differences in calculated equilibrium adsorption capacity, $q_{e, c a l}$ with experimental equilibrium adsorption capacity, $q_{e, e x p}$ are low and the values of the correlation coefficients $\left(\mathrm{R}^{2}\right)$ are 0.9967 to 1.000 when used initial concentration $80 \mathrm{mg} . \mathrm{L}^{-1}$ to $120 \mathrm{mg} . \mathrm{L}^{-1}$. The complete data were listed in Table 5.

\subsection{Effect of $\mathrm{pH}$}

Figure 10 displays the effect of $\mathrm{pH}$ on the methylene blue adsorption on EGS-600 adsorbent. The adsorption of methylene blue dye was unaffected in the $\mathrm{pH}$ range of 4-8. Absorption

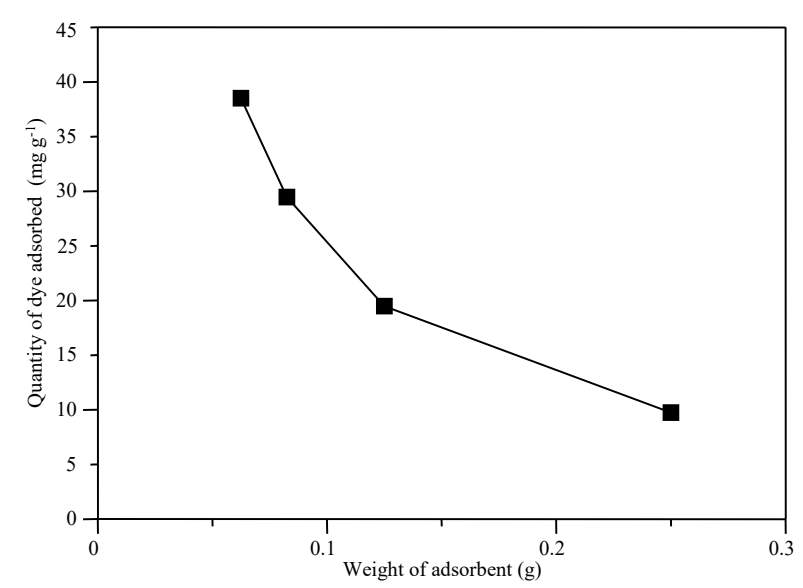

Figure 11. Effect of adsorbent dose on quantity of Methylene Blue dye adsorbed $\left(\mathrm{mg} \mathrm{g}^{-1}\right)$. Conditions: (pH: 6.9, MB: $100 \mathrm{mg} \mathrm{L} \mathrm{m}^{-1}$, weight adsorbent: $62.5 ; 82.5 ; 125$ and $250 \mathrm{mg}$, at $25^{\circ} \mathrm{C}$ ) at $\mathrm{pH}$ less than 3 was not beneficial as the excess hydrogen ions $\left(\mathrm{H}^{+}\right)$may have caused competition in absorption between the positive charge sites of methylene blue dye with hydrogen ions $\left(\mathrm{H}^{+}\right)[3,9]$. At $\mathrm{pH}$ value of dye solution more than 9 , the adsorption of methylene blue dye tends to decrease due to the excess number of negative charged sites of hydroxide ions $\left(\mathrm{OH}^{-}\right)$[9].

\subsection{Effect of Adsorbent Dosage}

Figure 11 shows the effect of adsorbent dosage on the quantity of methylene blue dye adsorbed (mg.g ${ }^{-1}$ ). The adsorbent quantity used in the adsorption is important to determine the quantity of dye adsorbed per unit weight of adsorbent in the system. The quantity of dye adsorbed per unit weight of adsorbent decreased when the dosage of adsorbent increased. This phenomenon shows that the active sites of the adsorbent were more effective at low ratio of adsorbent/adsorbate. If the ratio of the adsorbent/adsorbate is high, this will cause many of the remaining active sites to be covered by the adsorbate, thus causing sorption of specific dye to be low. This result shows a similar tendency with a previous work that investigated the adsorption of methylene blue onto roots, stems and leaves of $E$. crassipes [2].

\subsection{Effect of Temperature}

Figure 12 shows the effect of temperature on the removal percentage of methylene blue dye. The removal percentage of methylene blue dye at varying temperatures increased from $64.94 \%$ to $99.90 \%$ (at room temperature), $77.16 \%$ to $99.92 \%$ (at $40^{\circ} \mathrm{C}$ ) and $79.21 \%$ to

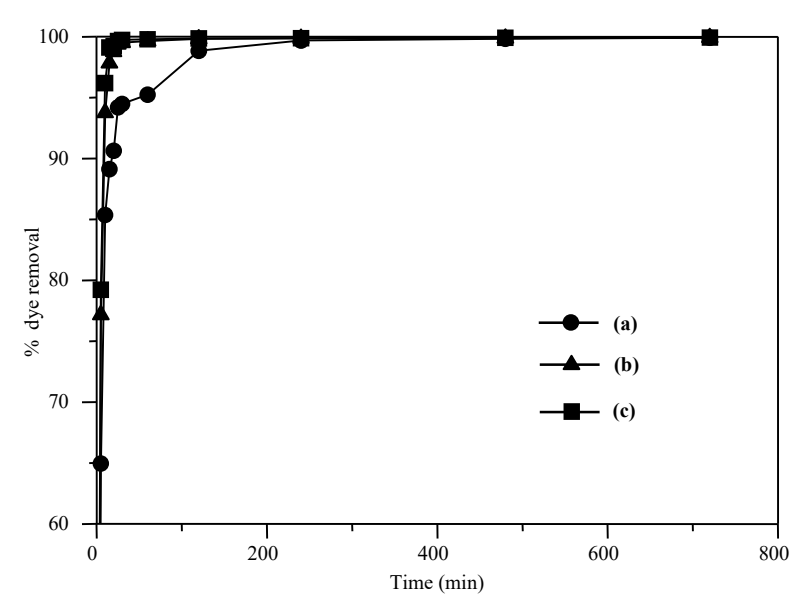

Figure 12. Effect of temperature on methylene blue dye sorption (\%). Conditions: (pH: 6.9, MB: $100 \mathrm{mg} \mathrm{L}^{-1}$, temperature (a) $25^{\circ} \mathrm{C}$, (b) $40^{\circ} \mathrm{C}$ and (c) $50^{\circ} \mathrm{C}$ ) 
$99.92 \%$ (at $50^{\circ} \mathrm{C}$ ). It can be clearly seen that by increasing the temperature, the removal percentage of methylene blue dye also slowly increased and reached optimum at almost $99.92 \%$. As the adsorption capacity increased with adsorption temperature, this shows that the adsorption of methylene blue dye by sulfonated carbon from $E$. crassipes was endothermic in nature.

Parameters of thermodynamic were determined by the experiments carried out at different temperatures. The value changes of free energy $(\Delta G)$, enthalpy $(\Delta H)$, and entropy $(\Delta S)$ of adsorption were determined with the equation:

$$
\begin{gathered}
\log K_{C}=\frac{\Delta S}{2.303 R}+\frac{\Delta H}{2.303 R T} \\
\Delta G=\Delta H-T \Delta S
\end{gathered}
$$

where $\Delta S$ and $\Delta H$ are the changes in entropy and enthalpy of adsorption. A plot of $\log K_{C}$ vs. $1000 / T$ is linier with $K_{C}$ was calculated by the equation:

$$
K_{C}=\frac{C_{1}}{C_{2}}
$$

where $T$ is temperature (K); $\mathrm{R}$ is the gas con-

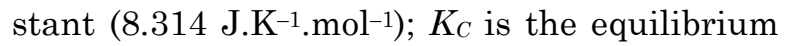
constant; $C_{1}$ is the quantity of methylene blue dye adsorbed per unit mass of adsorbent, and $C_{2}$ is the concentration of methylene blue dye in aqueous phase. Values of $\Delta S$ and $\Delta H$ are calculated from the slope and intercept of Van't Hoffs plots. Negative value of $\Delta G$ at each temperature indicates the feasibility and spontaneity of ongoing adsorption. The positive value of $\Delta S$ indicates the increase in randomness of ongoing process. The positive value of $\Delta \mathrm{H}$ indicates that the adsorption process is endothermic in nature.

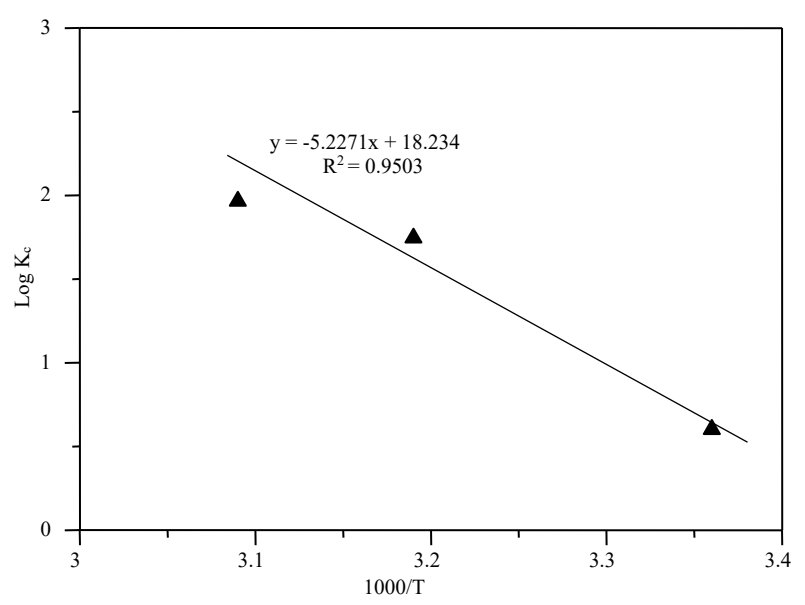

Figure 13. Van't Hoff's plots, $\log K_{c}$ vs. 1000/T
The thermodynamic parameters of $\Delta G, \Delta H$, and $\Delta S$ are calculated based on the slope and intercept of Van't Hoff's plots, as shown in Figure 13. The values of $\Delta G, \Delta H$, and $\Delta S$ were -109.38 kJ.mol ${ }^{-1},-100.08$ J.mol ${ }^{-1}$, and +349.13 J.K ${ }^{-1} \cdot \mathrm{mol}^{-1}$, respectively. Negative value of free energy $(\Delta G)$ indicates that the feasibility and spontaneity of ongoing methylene blue dye adsorption onto sulfonated carbon of $E$. crassipes as the adsorbent. The positive value of enthalpy $(\Delta H)$ indicates that the adsorption process of methylene blue dye by sulfonated carbon of $E$. crassipes as the adsorbent is endothermic in nature. The positive value of entropy $(\Delta S)$ indicates that the increase in degree of system irregularities.

\section{Conclusions}

E. crassipes (water hyacinth), a tropical plant can be used as the resources of low-cost adsorbent. The E. crassipes that was modified by carbonation followed sulfonated can be obtained good and low-cost adsorbent for methylene blue adsorption in aqueous solution. The ability of EG and EGS-600 adsorbent were investigated in batch system at methylene blue dye initial concentration of $100 \mathrm{mg} . \mathrm{L}^{-1}$ at room temperature. The sorption capacity of EGS-600 was better than EG adsorbent which can be proven of the value of equilibrium sorption experiment $\left(q_{e, e x p}\right)$ of both adsorbent was 18.517 mg.g $\mathrm{g}^{-1}$ (EG) and $19.480 \mathrm{mg} \cdot \mathrm{g}^{-1}$ (EGS-600). Adsorption processes of both adsorbent for methylene blue dye adsorption in aqueous solution follow pseudo-second-order kinetics models with the rate constant 0.0521 g.mg ${ }^{-1} \cdot \mathrm{min}^{-1}$ (EG) and 0.2891 g.mg ${ }^{-1} \cdot \mathrm{min}^{-1}$ (EGS-600). The adsorption process onto both adsorbents took place through a multi-layer adsorption mechanism that were illustrated well by Freundlich isotherm model with correlation coefficient, $\mathrm{R}^{2}$, of 0.9996 (EG) and 0.9935 (EGS-600). The free energy thermodynamic parameters showed a negative value $\left(-109.38 \mathrm{~kJ} . \mathrm{mol}^{-1}\right)$, which indicates that the adsorption process of methylene blue dye on EGS-600 was spontaneous.

\section{Acknowledgements}

The authors gratefully acknowledge research funding from Islamic Development Bank (IDB) project and Faculty of Teacher Training and Education, Universitas Mulawarman, East Kalimantan Province, Indonesia. 


\section{References}

[1] Yi, J.Z., Zhang, L.M. (2008). Removal of methylene blue dye from aqueous solution by adsorption onto sodium hu mate/polycrylamide/clay hybrid hydrogels, Bioresour. Technol. 99: 2182-2186.

[2] Wanyonyi, W.C., Onyari, J.M., Shiundu, P.M. (2013). Adsorption of Methylene Blue Dye from Aqueous Solution Using Eichhornia crassipes, Bull. Environ. Contam. Toxicol. 91(3): 362-366.

[3] Kumar, P.S., Ramalingam, S., Sathishkumar, K. (2011). Removal of methylene blue dye from aqueous solution by activated carbon prepared from cashew nut shell as a new low-cost adsorbent. Korean J. Chem. Eng., 28(1): 149-155.

[4] Nigam, P., Armour, G., Banat, L.M., Singh, D., Marchant, R. (2000). Physical removal of textile dyes from effluents and solid-sate fermentation of dye-adsorbed agriculturalresidues. Bioresour. Technol. 72: 219-226.

[5] Alinsafi, A., Khemis, M., Pons, M.N., Leclerc, J.P., Yaacoubi, A., Benhammou, A., Nejmeddine, A. (2005). Electro-coagulation of reactive textile dyes and textile wastewater. Chem. Eng. Process. 44: 461-470.

[6] Alkan, M., Celikcapa, S., Demirbas, O., Dogan, M. (2005). Removal of reactive blue 221 and acid blue 62 anionic dyes from aqueous solution by sepiolite. Dyes and Pigments, 65: 251-259.

[7] Karaoglu, M.H., Dogan, M., Alkan, M. (2010). Removal of Reactive Blue 221 by Kaolinite from Aqueous Solution. Ind. Eng. Chem. Res., 49:1534-1540.

[8] Pelekani, C., Snoeyink, V.L. (2000). Competitive adsorption between antrazine and methylene blue on activated carbon: the importance of pore size distribution. Carbon, 38: 1423-1436.

[9] Pavan, F.A., Mazzocato, A.C., Gushikem, Y. (2008). Removal of methylene blue dye from aqueous solution by adsorption using yellow passion fruit peel as adsorbent. Bioresour. Technol., 99: 3162-3165

[10] Sun, Q., Yang, L. (2003). The adsorption of basic dyes from aqueous solution on modified peat-resin particle. Water Research, 37: 15351544.

[11] Muthukumar, M., Selvakumar, N. (2004). Studies on the effect of inorganic salts on decolouration of acid dye effluent by ozonation. Dyes and Pigments, 62: 221-228.

[12] Sikaily, A.E., Khaled, A., Nemr, A.E., Abdelwahab, O. (2006). Removal of Methylene Blue from aqueous solution by marine green alga Ulva lactuca. Chem. Ecol., 22: 149-157.

[13] Park, C., Lee, M., Lee, B., Kim, S.W., Chase, H.A., Lee, J., Kim, S. (2007). Biodegradation and biosorption for decolorization of synthetic dyes by Funalia trogii. Biochem. Eng. J., 36: 59-65.

[14] Wanyonyi, W.C., Onyari, J.M., Shiundu, P.M. (2014) Adsorption of Congo Red Dye from Aqueous Solution Using Roots of Eichhornia Crassipes: Kinetic and Equilibrium Studies Energy. Procedia, 50: 862-869.

[15] Sivaraj, R., Venckatesh, R., Gowri, Sangeetha, G. (2010). Activated Carbon Prepared From Eichornia Crassipes as an Adsobent for the Removal of Dyes from Aqueous Solution. Int. J. Eng. Sci. and Tech. 2(6,) 2418-2427.

[16] Giri, A.K., Patel, R., Mandal, S. (2012). Removal of $\mathrm{Cr}(\mathrm{VI})$ from aqueous solution by Eichhornia crassipes root biomass-derived activated carbon. Chem. Eng. J., 185-186: 7181.

[17] Gupta, G.S., Prasad, G., Panday, K.K., Singh, V.N. (1988). Removal of Chrome Dye from Aqueous Solution by Fly Ash, Water, Air and Soil Pollution, 37: 13-24.

[18] Lim, H.K., Teng, T.T., Ibrahim, M.H., Ahmad, A., Chee, H.T. (2012). Adsorption and Removal of Zinc (II) from Aqueous Solution Using Powdered Fish Bones. APCBEE Procedia, 1: 96-102.

[19] Acemioglu, B., Almay, M.H. (2001). Equilibrium Studies on Adsorption of $\mathrm{Cu}$ (II) from Aqueous Solution onto Cellulose. J. Colloid Interface Sci. 243: 81-84.

[20] Zawahry, M.M.E., Kamel, M.M. (2004). Removal of azo and anthraquinone dyes from aqueous solutions by Eichhornia Crassipes. Water Research, 38: 2967-2972.

[21] Low, K.S., Lee, C.K., Tan, K.K. (1995). Biosorption of Basic Dyes by Water Hyacinth Roots. Bioresour. Technol., 52: 79-83.

[22] Teng, H., Tu, Y.T., Lai, Y.C., Lin, C.C. (2001). Reduction of $\mathrm{NO}$ with $\mathrm{NH}_{3}$ over carbon catalysts: The effects of treating carbon with $\mathrm{H}_{2} \mathrm{SO}_{4}$ and $\mathrm{HNO}_{3}$. Carbon, 39(4): 575582

[23] Nurhadi, M., Chandren, S., Yuan, L.S., Ho, C.S., Mahlia, T.M.I., Nur, H. (2017). Titania-Loaded Coal Char as Catalyst in Oxidation of Styrene with Aqueous Hydrogen Peroxide. Int. J. Chem. Reactor Eng., 15(1): 1-11.

[24] Nurhadi, M. (2017). Modification of Coal Char-loaded $\mathrm{TiO}_{2}$ by Sulfonation and Alkylsilylation to Enhance Catalytic Activity in Styrene Oxidation with Hydrogen Peroxide as Oxidant. Bulletin of Chemical Reaction Engineering \& Catalysis, 12(1): 55-61. 
[25] Nurhadi, M. (2017). Epoxidation of 1-Octene with hydrogen peroxide aqueous catalyzed by titania supported sulfonated coal. American Institute of Physics, 1813( 030001)

[26] Geng, L., Wang, Y,. Yu, G., Zhu, Y. (2011). Efficient carbon-based solid acid catalysts for the esterification of oleic acid. Catal. Commun. 13(1): 26-30.

[27] Liu, Y., Chen, J., Yao, J., Lu, Y., Zhang, L., Liu, X. (2009). Preparation and properties of sulfonated carbon-silica composites from sucrose dispersed on MCM-48. Chem. Eng. J., 148(1): 201-206.
[28] Nurhadi, M., Efendi, J., Lee, S. L., Mahlia, T. M. I., Chandren, S., Ho, C. S., Nur, H. (2015). Utilization of low rank coal as oxidation catalyst by controllable removal of its carbonaceous component. J. Taiwan Institute Chem. Eng., 46: 183-190.

[29] Ho, Y.S., McKay, G. (1998). Sorption of dye from aqueous solution by peat. Chem. Eng. J., 70: $115-124$. 